\title{
Use of Continuous Regional Anesthetic for Management of Pediatric Sickle Cell Crisis
}

\author{
Julie T. Vuong, Milena Pilipovic
}

Department of Anesthesiology, Penn State Hershey Medical Center, Hershey, USA.

Email: jvuong@hmc.psu.edu

Received August $7^{\text {th }}, 2012$; revised September $10^{\text {th }}, 2012$; accepted September $25^{\text {th }}, 2012$

\begin{abstract}
Sickle cell patients often find difficulty obtaining adequate treatment of pain. Anti-inflammatory medications, steroids, and opioids can reduce pain; however their use is limited by side effects. We present a 12 -year-old female with sickle cell disease who was admitted with severe right thigh pain secondary to acute infarction of the proximal femoral diaphysis.She was treated with intravenous hydration, ketorolac and opioids with no relief. The patient agreed to a continuous femoral nerve block, which was done under sedation. Pain relief was obtained immediately. The infusion was discontinued after 3 days and the patient was discharged the day after catheter removal with a one week supply of fentanyl patches and home dose of oral oxycodone. We suggest continuous femoral nerve block as an adjunct to treat sickle cell pain crises involving the lower extremity. Regional techniques may vasodilate and thus improve the nociceptive, vasoconstrictive pain associated with acute pain crises.
\end{abstract}

Keywords: Sickle Cell Crisis; Regional Anesthesia; Pediatric Pain

\section{Case Report}

Although most patients with sickle cell disease first attempt to treat their acute pain episodes at home, acute pain crises are the most common cause for seeking medical attention in this population [1]. However, sickle cell patients often find difficulty obtaining adequate treatment of pain. There is often a reluctance to treat with high dose opioids, secondary to opioid side effects as well as a lingering uneasiness about possible drug seeking behavior. Regional anesthetic techniques are a useful adjuvant to a pain relief regimen which can encompass nonsteroidal anti-inflammatory drugs, acetaminophen, narcotics, and non-narcotic opioid-receptor binding drugs.

We present a 12-year-old, $38 \mathrm{~kg}$ African American female with hemoglobin SS disease who was admitted with her typical sickle cell crisis pain. She had attempted to manage 24 hours of $10 / 10$ pain at home with both oral ibuprofen and oxycodone without relief. She continued to describe severe, throbbing, non-radiating right thigh pain which persisted despite treatment with $0.6 \mathrm{mg}$ iv hydromorphone and $17.5 \mathrm{mg}$ iv ketoralac. After admission to the pediatric hematology service, laboratory evaluations revealed no infectious etiology and electrolytes and blood counts were within normal limits, including hemoglobin 12.1. She was given iv hydration, and for pain control she was continued on $17.5 \mathrm{mg}$ iv ketoralac every 6 hours with hydromorphone pca $0.2 \mathrm{mg}$ basal rate with bolus $0.2 \mathrm{mg}$ every 15 minutes as needed, in the setting of a history of intolerance to morphine which caused shortness of breath and a pruritic rash. Within a few hours of the dilaudid pca initiation, the patient developed a diffuse pruritic rash relieved with diphenhydramine, but the pca was discontinued and she was switched to oxycontin $10 \mathrm{mg} \mathrm{q} 12$ hours and oxycodone $5 \mathrm{mg} \mathrm{q} 4$ hours as needed, with iv dilaudid as breakthrough relief. MRI of her right leg revealed acute infarction of the proximal femoral diaphysis and reactive myositis along the medial and lateral aspects of the femoral diaphysis. She received multiple doses of intermittent hydromorphone without adequate relief, whereupon the acute pain service was consulted.

After discussion with patient, family, and primary service, a femoral nerve block was agreed upon, utilizing a catheter to provide continuous ropivicaine infusion. However, secondary to anxiety, the patient and family requested sedation for placement of the catheter. This was done uneventfully under propofol infusion $80 \mathrm{mcg} / \mathrm{kg} /$ minute with standard ASA monitors and a nasal cannula with end tidal $\mathrm{CO}_{2}$ monitoring, titrated to oxygen saturation of $\geq 98 \%$ in a post-anesthesia acute care bed. We used ultrasound guidance as well as a nerve stimulator to place the femoral nerve catheter under sterile technique and infused a single dose of $8 \mathrm{cc}$ of $2 \%$ lidocaine for immediate relief. The catheter was sterilely dressed and an 
infusion pump was programmed for the continuous ropivicaine infusion. The patient recovered from the procedural sedation of 30 minutes without issues, vital signs stable, and was returned to her floor bed with a $0.2 \%$ ropivicaine infusion run over the following 3 days. The infusion rate was adjusted from $7 \mathrm{ml} / \mathrm{h}$ to $3 \mathrm{ml} / \mathrm{h}$ secondary to concerns of numbness, and by day 3 the infusion was discontinued after sufficient pain control using fentanyl patch at $50 \mathrm{mcg} / \mathrm{h}$ and oral oxycodone, home dose. On day 4, after her pain had been controlled, the catheter was pulled, and the patient discharged to home with one week of fentanyl patches and oxycodone.

\section{Discussion}

Acute pain control in sickle cell crisis should involve consideration of regional anesthetic techniques. An acute pain crisis is often described as primarily nociceptive rather than neuropathic pain, as they are often vaso-occlusive episodes involving ongoing ischemia and infarction [2]. The pain may involve multiple sites and arises from the cortical pressure following inflammation and edema, and can occur without identifiable triggers. A Cochrane review of pain management for acute sickle cell pain crises in children and adults showed that anti-inflammatory medications given parenterally could reduce pain, and that morphine given by mouth was as effective as injection in children, with no difference in side effects [3]. Also, steroids were suggested to shorten a pain episode and reduce the need for analgesics. Regional anesthetic techniques have also been proven beneficial, and there is currently a study ongoing to determine feasibility of single-shot femoral nerve blocks in patients admitted to the emergency department in acute pain crises involving the lower extremities [4]. Our success with a continuous infusion of ropivicaine via femoral nerve catheter was met with relief from patient, family, and primary service in light of minimal adverse events. While there are four phases of acute pain episodes: prodromal, initial infarctive, post-infarctive, and resolving, we propose offering a continuous catheter when the patient presents for admission for acute pain. At that time the patient likely is in the initial infarctive phase, having failed home analgesics during the prodromal phase, and can be given a loading dose of local anesthetic after placement of the femoral catheter and then titrated via continuous infusion throughout the initial infarctive and post-infarcttive phases. The infusion can be turned off and the pa- tient transitioned to oral and or transdermal medications for the resolving phase and the catheter removed after resolution of the pain crisis. As the hallmark of sickle cell pain crisis is vasocclusive pain, commonly avascular necrosis of bone marrow in lumbar, femur, and knees $[5,6]$, we propose that femoral nerve catheters would be an excellent adjunct for patients who have pain in the lower extremity. Epidural analgesia has been proven safe and effective in treating children in acute pain crises, and improved oxygenation significantly in a previous study due to relief of opioid induced respiratory depression or pain-induced splinting, as well as controlling severe pain unresponsive to high dose opioids [7]. Thus, regional techniques for distal pain in one extremity may vasodilate and thus improve the nociceptive, vasoconstrictive pain associated with acute pain crises.

\section{REFERENCES}

[1] O. S. Platt, D. T. Bruce, J. B. Donald, F. M. Paul, F. R. Wendell, V. Elliott and R. K. Thomas, "Pain in Sickle Cell Disease-Rates and Risk Factors," The New England Journal of Medicine, Vol. 325, No. 1, 1991, pp. 1116. doi:10.1056/NEJM199107043250103

[2] J. J. Field and M. R. DeBauen, "Acute Pain Management in Adults with Sickle Cell Disease," 2012.

http://medjournal.hmc.psu.edu:4219/contents/acute-pain-ma nagement-in-adults-with-sickle-cell-disease? source=search_result\&search $=$ sickle + cell + pain + management\&selectedTitle $=$ $1 \% 7 \mathrm{E} 150$

[3] R. Dunlop and K. C. L. B. Bennett, "Pain Management for Sickle Cell Disease in Children and Adults," Cochrane Database of Systematic Reviews, No. 2. 2006, Article ID: CD003350. doi:10.1002/14651858.CD003350.pub2

[4] J. Glassberg, "Regional Anesthesia for Sickle Cell Crisis Using Ultrasound in the Emergency Department: Phase I (RESCUED)," 2012. http://clinicaltrials.gov/ct2/show/NCT01256281

[5] P. G. Firth, C. A. Head and D. C. David, "Sickle Cell Disease and Anesthesia," Anesthesiology, Vol. 101, No. 3, 2004, pp. 766-785.

[6] C. B. Berde and F. S. Navil, "Analgesics for the Treatment of Pain in Children," The New England Journal of Medicine, Vol. 347, No. 14, 2002, pp. 1094-1103.

[7] M. Yaster, R. T. Joseph, B. Carol, F. C. James and D. George, "Epidural Analgesia in the Management of Severe Vaso-Occlusive Sickle Cell Crisis," Pediatrics, Vol. 93, No. 2, 1994, pp. 310-315. 